\title{
Topologia e tipologia, a parcela gótica
}

\author{
Jesús Conde-García \\ Grupo de Investigación Galicia Cidade e Territorio. DPAUC. Escola de Arquitectura. Universidade da \\ Coruña. E-mail: jesusconde@coag.es
}

Submetido em 15 de junho de 20181. Aceito em 2 de dezembro de 2019.

\begin{abstract}
Resumo. O conceito de topologia encontra-se perfeitamente definido "estuda certas propriedades das figuras geométricas, entre elas estão aquelas que não variam quando as figuras são deformadas", enquanto a tipologia tem uma acepción bem mais ampla e indefinida: "estudo dos traços característicos de uma série de dados”, no entanto sua visão conjunta ajudanos a aprofundar no entendimento do tipo arquitectónico. A cidade histórica européia apresenta uma série de características comuns: sua adaptação tanto geográfica como topográfica, e uma racionalidade construtiva onde os muros pétreos são os elementos fundamentais. Os diferentes esquemas viarios articulam um parcelario muito variado onde os grandes edifícios monumentales convivem com o caserío. A unidade elementar deste mosaico é a parcela gótica. No caso de Santiago de Compostela estas características estão muito acentuadas e a paisagem urbana vem determinado pelo contraste entre o caserío menudo -derivado da parcelación medieval-e as fábricas dos grandes monumentos religiosos. Deste modo um padrão singelo, baseado na relação entre parcela gótica e rua, somado a duas estratégias muito diferentes de adaptação topográfica, dá lugar a uma estrutura urbana extraordinariamente rica e complexa. A investigação sobre o tipo, que tem como suporte a realização de um projecto arquitectónico concreto, é o objeto deste artigo.
\end{abstract}

Palavras-chave. tipo, padrões, tipologia, reabilitação, cidade histórica.

\section{O tipo}

A ideia de tipo sempre tem estado presente às teorias que sobre a arquitectura e o projecto arquitectónico se sucedem ao longo da história: umas pretendem a construir, outras "reconstruí-la" e algumas inclusive a destruir. Em qualquer caso, não cabe dúvida que faz parte do incerto processo de criação de uma obra de arquitectura. Se consideramos que o tipo é um "conceito que descreve um grupo
"A casa é imaginada como um ser vertical. Eleva-se. A escada que vai ao sótano se baixa sempre. A escada do desván, mais empinada, mais tosca, sobe-se sempre."

Bachelard, 1957

de objetos caracterizados por ter a mesma estrutura formal" (Moneo, 1978) é inevitável que assomem, com maior ou menor clareza, séries, classes, famílias e géneros que percorrem transversalmente o pensamento arquitectónico. Ainda supondo que tentemos estabelecer uma metodologia proyectual oposta à presunção do tipo, no momento de definição morfológica aparecerão analogias procuradas ou não. A noção do tipo permite 
ao arquitecto propor associações, grupos e relações que apresentam uma sólida base teórica, mas ao mesmo tempo são maleáveis e transformables.

$\mathrm{Na}$ estrutura formal que constitui o núcleo essencial do tipo podemos distinguir aquelas características que dependem das relações que estabelecem entre si as diferentes partes do objeto de estudo como continuidade, compacidad ou conectividade, que são estudadas pela 'topologia', e outras estritamente geométricas onde conceitos como a dimensão e a escala são determinantes. A topologia é um ramo das matemáticas dedicada ao estudo daquelas propriedades dos corpos geométricos que permanecem inalteradas por transformações contínuas. Interessa-se por conceitos como 'proximidade', 'número de buracos', ou 'consistência': estas propriedades dos corpos poder-se-iam definir como relacionales em contrate com aquelas outras intrinsecamente geométricas que poderíamos adjetivar como dimensionais. É evidente que a arquitectura trabalha com ambas.

Na concepção de um novo edifício outras noções implícitas no conceito de tipo, tais como a história ou o uso, se nos apresentam como dados teóricos. Constituem instrumentos ou ferramentas úteis ao longo do processo de desenho e que fazem parte do método de projecto. Em mudança, quando se trata de reabilitar um edifício tais conhecimentos se tornam realidades empíricas concretas que constituem um momento na evolução do objeto arquitectónico, uma etapa de sua vida. Nosso trabalho como arquitectos é guiar essa continuidade e transformação 'tipológica'.

Quadro 1. Características da moradia em parcela gótica (fonte: elaborada pelo autor).

Condições topológicas (relacionales)

Adição no sentido da rua.

Adição de plantas (entre 1-5 em media)

Conexão entre plantas (escada, eixo vertical)

Contacto com a rua: ocos, luz

Contacto com o patio: ocos, luz
Condições geométricas

(dimensionais)
Muros medianeros paralelos entre si.

Muros medianeros perpendiculares a rúa.

Muros medianeros separados unha distância determianda longitude das vigas de madeira 

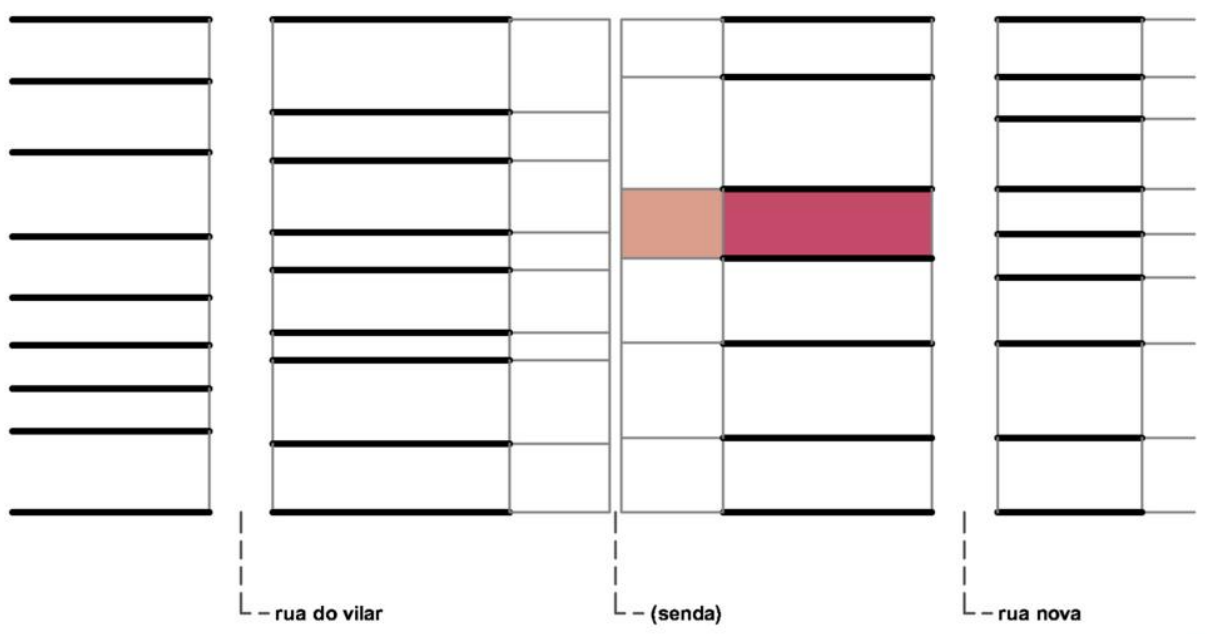

Figura 1. Padrão tipológico genérico de uma parte da Cidade Histórica de Santiago de Compostela. Às vezes entre as parcelas góticas opostas aparece uma senda, um acesso secundário, que também assumia funções de colector de águas sujas. A série cale-edifício-pátio-(senda)-pátio-edifício-cale, repetida linealmente constitui o padrão organizativo (fonte: elaborada pelo autor).

No exemplo que se pretende mostrar aqui uma pequena moradia no centro histórico de uma cidade européia- é a parcela gótica a que determina a razão tipológica das edificaciones. A obtenção do maior número de parcelas na menor longitude de rua, bem como a lógica estrutural na eleição da distância de separação dos muros portantes, explicam a origem deste tipo. A unidade elementar de construção do centro histórico, a 'tesela' básica com que se forma este complexo mosaico, é por tanto a parcela gótica. Os usos quotidianos da cidade têm cabida neste tipo arquitectónico. As plantas altas dedicam-se ao uso residencial enquanto os térreos, em contacto estreito com a rua e o pátio, albergam as actividades económicas: desde usos agropecuários, até pequenas oficinas artesanais, passando por lojas e comércios. A parcela gótica, sua repetição ao longo da rua, é a base do padrão organizativo. A série cale-edifício-pátio(senda)-pátio-edifício-cale, repetida linealmente constitui o esquema básico.

Como dizíamos numa estrutura formal podemos distinguir, parâmetros topológicos (relacionales) e outros puramente geométricos (dimensionais) a esencia tipológica vem determinada por ambos. Por exemplo, se numa parcela gótica, devido a sucessivas transformações, se colmata a parcela e desaparece o pátio, também se perdem as aberturas e ocos do 'fundo' do edifício, pelo que a luz e ventilación cruzadas que são umas das qualidades mais interessantes deste espaço se desvanecem: ainda que as dimensões permanecem quase inalteradas produz-se uma transformação radical do tipo. Do mesmo modo, se realizase uma divisão horizontal da propriedade a geometria não se altera substancialmente, mas se perde o eixo vertical de conexão espacial que é parte fundamental da natureza tipológica. Por outro lado, se unificarmos três parcelas em um, as proporções e dimensões da unidade do projeto são alteradas e, por tanto, o tipo tambén muda.

Uma leitura da cidade baseada no conceito de tipo remete-nos ao pioneiro Plano Urbanístico para o Centro Histórico de Bolonha (1969), onde as teorias morfotipológicas sobre a construção, transformação e conservação do tecido da cidade, derivadas de uma análise minucioso dos processos edilicios e seu entendimento tipológico, foram postas em prática pela primeira vez mediante um instrumento urbanístico. No caso galego temos de tomar como referência o plano de Santiago elaborado no marco dos trabalhos de redacção do Plano Especial de 
Protecção e Reabilitação da Cidade Histórica (Dalda e Viña, 1986). Este interessante mapa mostra o térreo de todas as edificaciones -não só dos monumentos históricos- pondo de relevo a versatilidad da parcela gótica na formação da estrutura urbana. Apresenta uma análise do tecido 'menudo' necessário para entender o valor patrimonial das 'modestas' edificaciones residenciais.

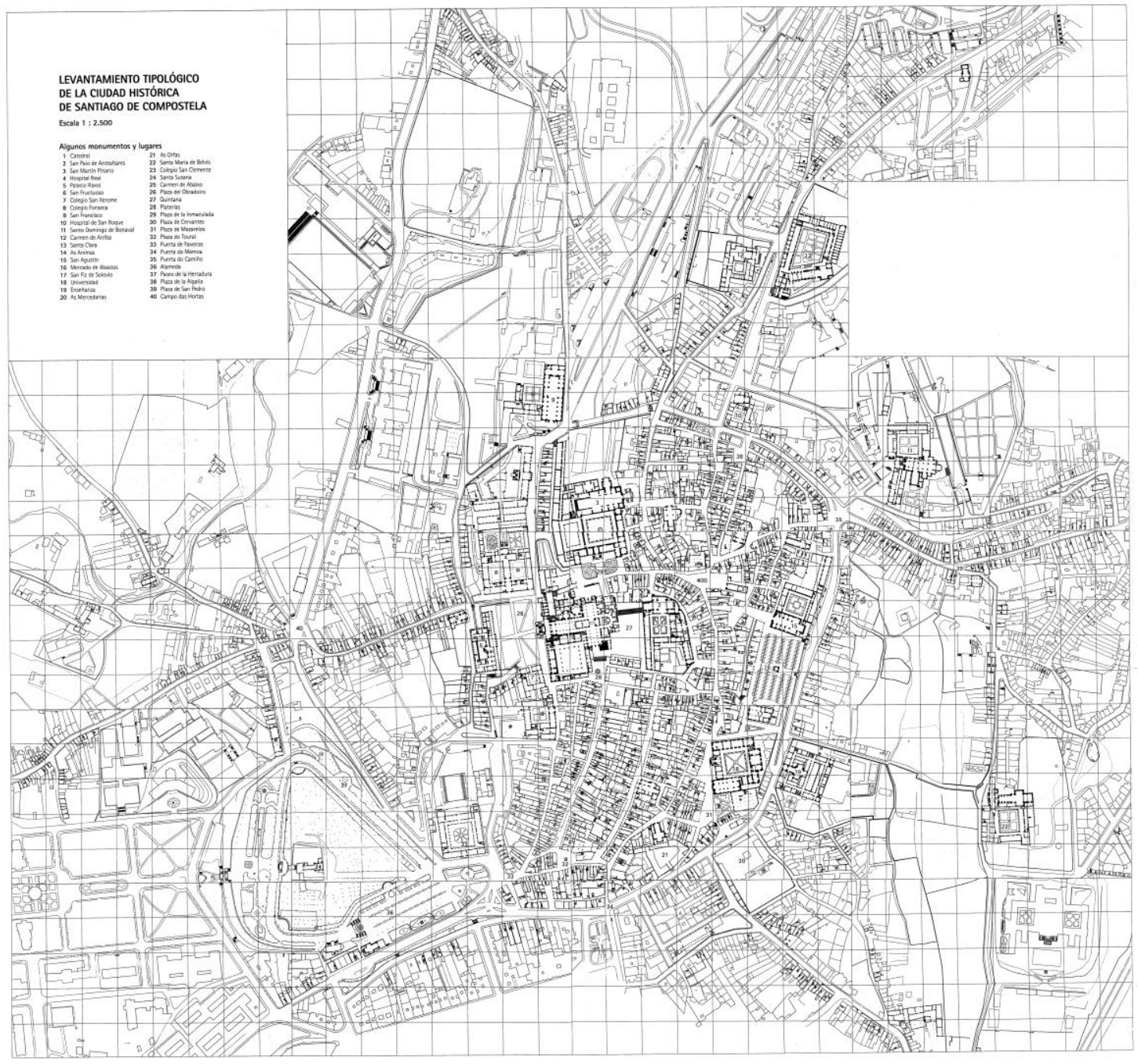

Figura 2. Levantamento Tipológico da Cidade Histórica de Santiago de Compostela, E 1:500. Dalda, Juan Luís. Viña, Anxel (1986), oficina de Planeamiento S.A (fonte: em Martí Arís, Carlos. Santiago de Compostela: A cidade histórica como presente. Santiago: Consórcio da Cidade de Santiago de Compostela, 1995).

\section{Santiago de Compostela}

A relevância de Santiago sem dúvida vem suscitada por sua condição de ponto final de peregrinación. Não cabe dúvida de que o Caminho de Santiago se constituiu num fluxo contínuo de gente, cultura, ideias, valores, etc., que impregnaram a cidade e impulsionaram seu desenvolvimento. Um nexo fortísimo com o norte de Europa que tem resultado decisivo na evolução não só de Galiza sina de toda Espanha.

Santiago encontra-se entre as bacias de dois grandes rios o Ulla e o Tambre. Localizado na parte alta do curso de um afluente do Ulla -o rio Sar-, ocupa uma posição estratégica na conexão do mar com uma ampla comarca interior pelo que dois villas costeras: uma de ria-a de Arousa, Padrón, e outra para perto de a desembocadura do Tambre, Noia, têm sido 
seus portos naturais para o Atlántico. Por outro lado faz parte do eixo que com direcção norte-sul articula as principais zonas urbanas costeras de Galiza. Estas duas razões geográficas explicam a importância histórica deste enclave.

Construída sobre uma elevação, um 'morro' rodeado pelos rios Sar e sua afluente o Sarela, numa geografia de suaves colinas, a cidade estabelece uma íntima relação paisajística com o médio natural que se manteve até nossos dias. Esta estreita vinculação com o meio é especialmente clara na fachada poente da cidade, a mais monumental e emblemática, que será a mais representada ao longo da história em inumeráveis vistas.

Aproveitando-se destas favoráveis condições geográficas o lugar tem estado habitado desde a antiguidade. $\mathrm{Na}$ época romana situava-se aqui um pequeno assentamento, uma 'mansio', isto é uma parada de descanso, sobre traça-a da via XIX. O lugar era um nodo de comunicações importante ao confluir nele numerosas sendas secundárias que articulavam uma vasta região; mas não será até a alta Idade Média quando este pequeno enclave começará a se consolidar como um núcleo importante. A descoberta de um antigo mausoleo romano no século IX, que o bispo de Iria Flavia vai identificar como o sepulcro do Apóstol Santiago, provocará um culto que rapidamente se estendeu por toda Europa, convertendo a Santiago de Compostela (junto com Roma e Jerusalém) numa das cidades santas da Cristiandad. Durante os séculos posteriores a tumba do apóstol converter-se-á num lugar de peregrinación ao que vão gentes de toda Europa.
A partir deste momento, apoiando-se no auge económico que implica o fenómeno da peregrinación, o crescimento da população vai ser contínuo. As sucessivas expansões da cidade histórica têm estado acompanhadas de ampliações de suas muralhas. A muralha medieval não só prestava serviços de defesa, sina que permitia distinguir entre dois espaços de direito diferentes, isto é permitia a distinção efetiva entre o mundo agrário e a cidade. Já no século X Sisnando II levanta uma empalizada que praticamente engloba a atual almendra da cidade histórica ainda que naquele momento a edificación só ocupava alguns enclaves do recinto. No século XI o bispo Cresconio (1037-1068) constrói umas novas muralhas da cidade com uns dois quilómetros de longitude e que cercavam um recinto de umas 28 hectares. Esta traça se manteve sem variações significativas até o século XIX e ainda se pode ler sem dificuldade no tecido histórico.

Segundo o livro V do "Códice Calixtino", escrito entre 1135-1140, a muralha de a cidade contava com sete portas: a primeira chamava-se Francígena (atual porta do Camiño), a segunda Porta dá Pena (situada naquela época, na atual porta de San Roque), a terça Porta de Sofrades (atual Porta de San Francisco), a quarta Porta do Santo Peregrino (ou Porta dá Trinidade), a quinta Porta Falgueriis (Porta Faxeira), a sexta Porta de Susannis (Porta dá Mámoa) e a sétima Porta de Mazarelos. Posteriormente, no século XIII, abriu-se uma nova porta, 'a Nova Porta da Vila' (a atual Porta da Pena), bem como alguns acessos mais modestos, portas menores ou postigos, utilizadas simplesmente para o acesso peatonal, como o Postigo dá Algalia e o Postigo de Sanfiz. 


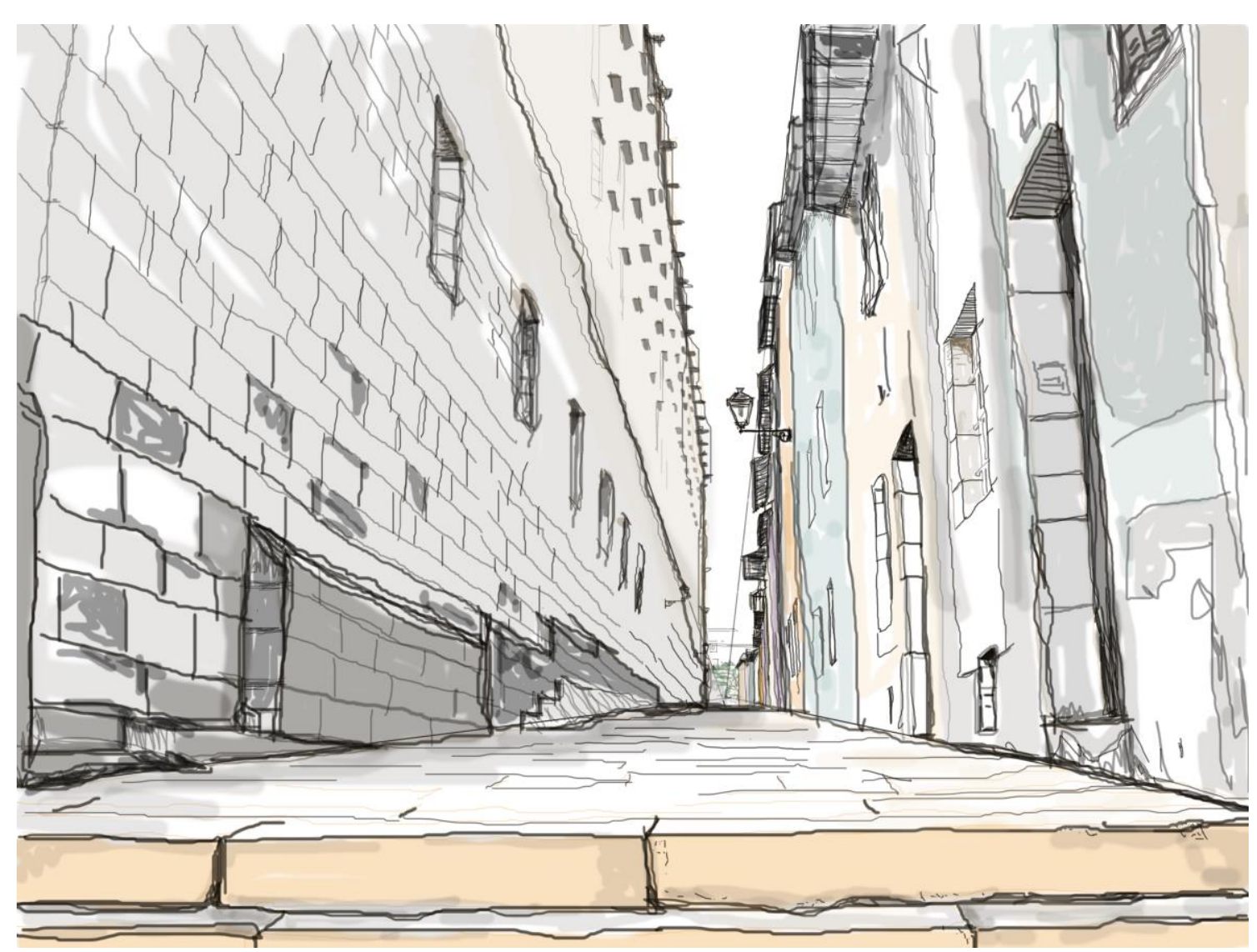

Figura 3. Desenho da Rúa do Val de Deus em Santiago. Com esta imagem ilustra-se o grande contraste existente entre as fábricas monacales -neste caso San Martiño Pinario- e as edificaciones domésticas (fonte: elaborada pelo autor).

\section{Os 'grandes contrastes'}

É ao redor da catedral onde se dispõem as praças mais importantes da cidade, não podia ser de outro modo, e à catedral em si mesma constitui um grande espaço público se utilizando muitas vezes como passo sobretudo quando o lluvioso clima de Santiago convida a se manter a coberto. O conjunto de praças em torno da fábrica catedralicia: Obradoiro, Platerías, Quintana, e Azabachería, constituem uma sequência urbana extraordinária. A cada uma destas praças é um atrio a uma das entradas à catedral: O Obradoiro na fachada principal ao oeste, Platerías na entrada ao transepto sul, a Azabachería no transepto norte e a Quintana ao este no acesso à Porta Santa.

Se as praças mais emblemáticas vão estar sócias aos grandes edifícios monumentales, as 'rúas' está-lo-ão às pequenas edificaciones que surgem nos caminhos que levam ao antigo 'locus Sancti Iacobus'. Sem dúvida a mais antiga é a rúa do Vilar que unia o recinto sagrado com um pequeno caserío situado ao sul, aproximadamente onde hoje se encontra a Porta Faxeira. No recinto intramuros não existiam parques públicos, e a presença vegetal estava associada a huertas e jardins privados já pertencessem aos grandes monasterios, ou a moradias particulares.

Como temos dito a estrutura urbana vem determinada pelo contrate entre o caserío menudo derivado da parcelación medieval e as fábricas dos grandes contêiners religiosos, esta relação é uma característica fundamental dos conjuntos históricos europeus mas na estrutura urbana de Santiago encontra um de seus máximos expoentes. Os imponentes edifícios das instituições religiosas modificarão a topografía mediante plataformas e muros de contenção, enquanto as estreitas parcelas adaptam-se ao relevo colmatando os 'intersticios'.

Os grandes edifícios constituem os 'sillares' do tecido, enquanto as moradias são as lascas 
e ripios com os que se recheiam as juntas entre eles. A parcela gótica é a unidade elementar neste processo de construção urbana. Esta intima relação entre actuações de escala muito diferente, tem como resultado um tecido urbano excelentemente travado, rico e heterogéneo, onde a surpresa e o contraste fazem parte de umas sequências urbanas às que as transformações barrocas têm sabido sacar o máximo partido.

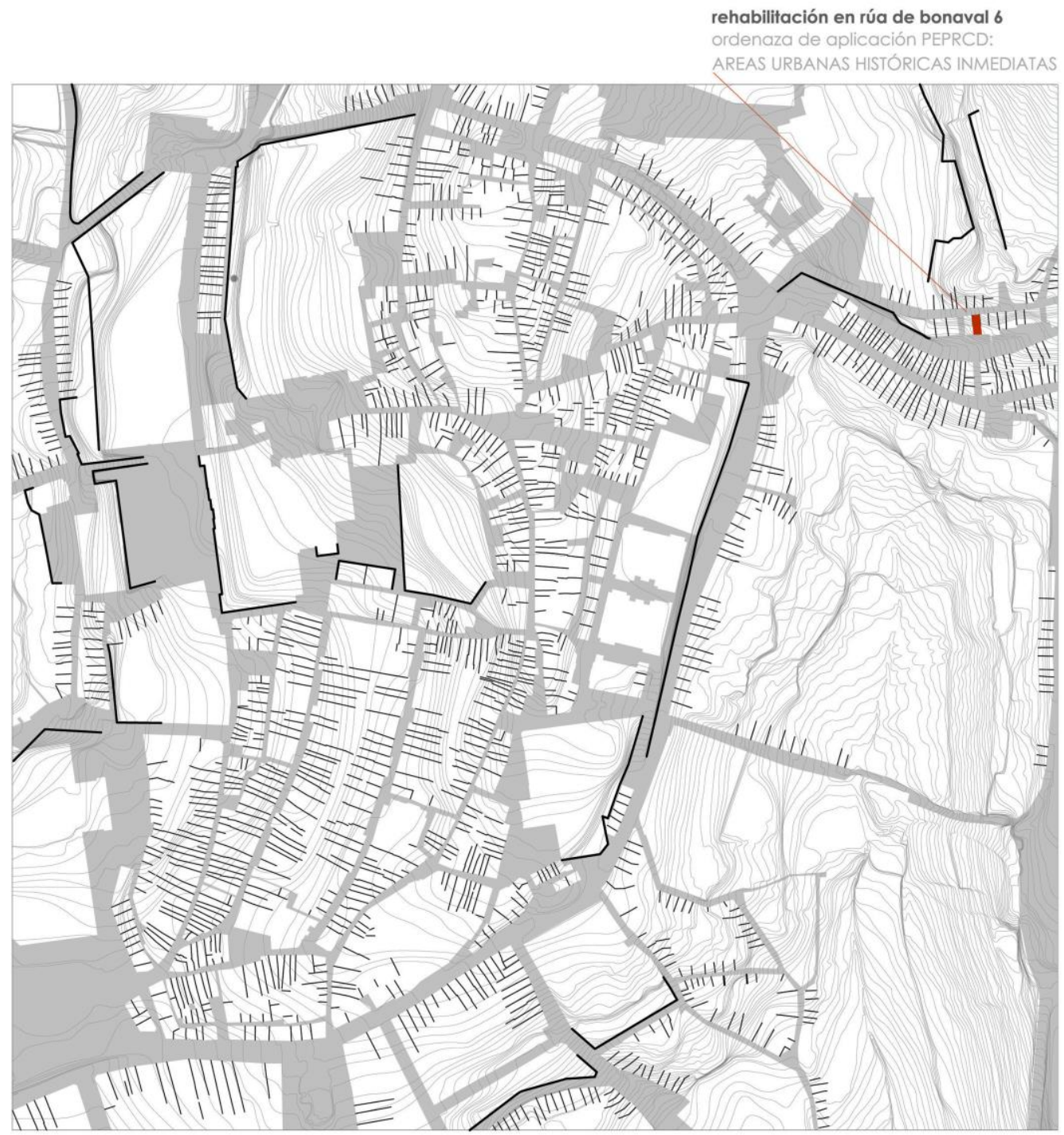

Figura 4. Planta de Santiago de Compostela que reflete o contraste existente entre as parcelas góticas e as grandes plataformas dos edifícios monumentales; o que supõe uma estratégia diferente de adaptação topográfica. Os muros medianeros são a base de um fraccionamiento da propriedade e de uma edificación que se amolda à topografía, enquanto os muros de contenção permitem a construção de bancales. Assinala-se assim mesmo a situação do projecto mencionado no artigo (fonte: elaborada pelo autor). 


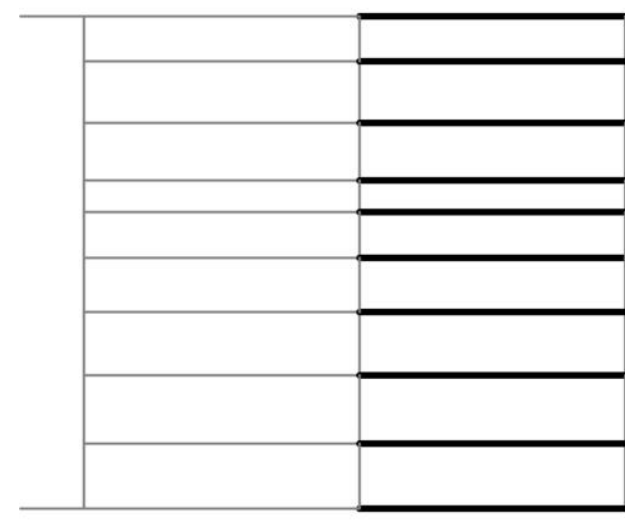

Figura 5. Esquema Tipológico de uma parte da Cidade Histórica de Santiago de Compostela, entre Bonaval e Belvís. Aprecia-se como o padrão genérico se adapta à topografía (fonte: elaborada pelo autor).
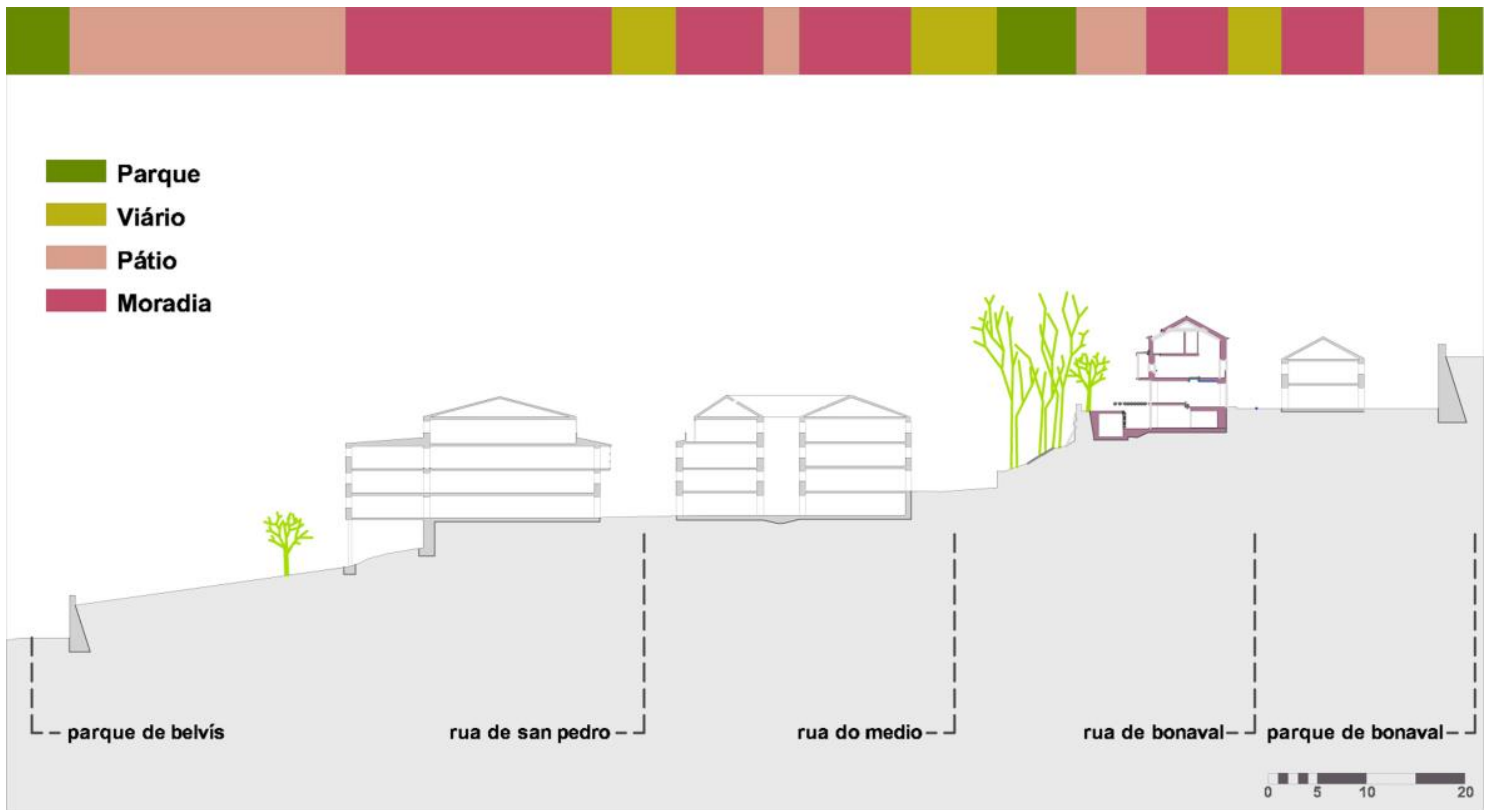

Figura 6. Secção de uma parte da Cidade Histórica de Santiago de Compostela, entre Bonaval e Belvís. Assinala-se a situação da moradia objeto de reabilitação (fonte: elaborada pelo autor).

\section{A reflexão proyectual}

Não cabe dúvida, por tanto, que no processo de desenho o conceito de tipo estará presente como um fundamento teórico que emerge apoiado por nossa formação arquitectónica. Em alguns momentos pode inclusive ser um convidado não 'desejado', mas no caso da reabilitação a noção de tipo constitui não só uma hipótese racional, sina uma parte intrínseca do objeto de intervenção.
A adaptação do tipo arquitectónico às condições topográficas é o que marcará a exclusividade da cada construção, permitindo, por um lado, uma grande diversidade de soluções particulares e por outro uma grande harmonia do conjunto. Este padrão flexível e adaptável é a que vai dar continuidade e trabazón ao espaço urbano, enquanto os pontos focais arraigam nos grandes monumentos, tanto religiosos como civis; obviamente os edifícios institucionais 
vão responder a tipos arquitectónicos diferentes que precisam uma estratégia de adaptação topográfica diferente.

A riqueza espacial da cidade histórica baseiase numa radical adesão às circunstâncias
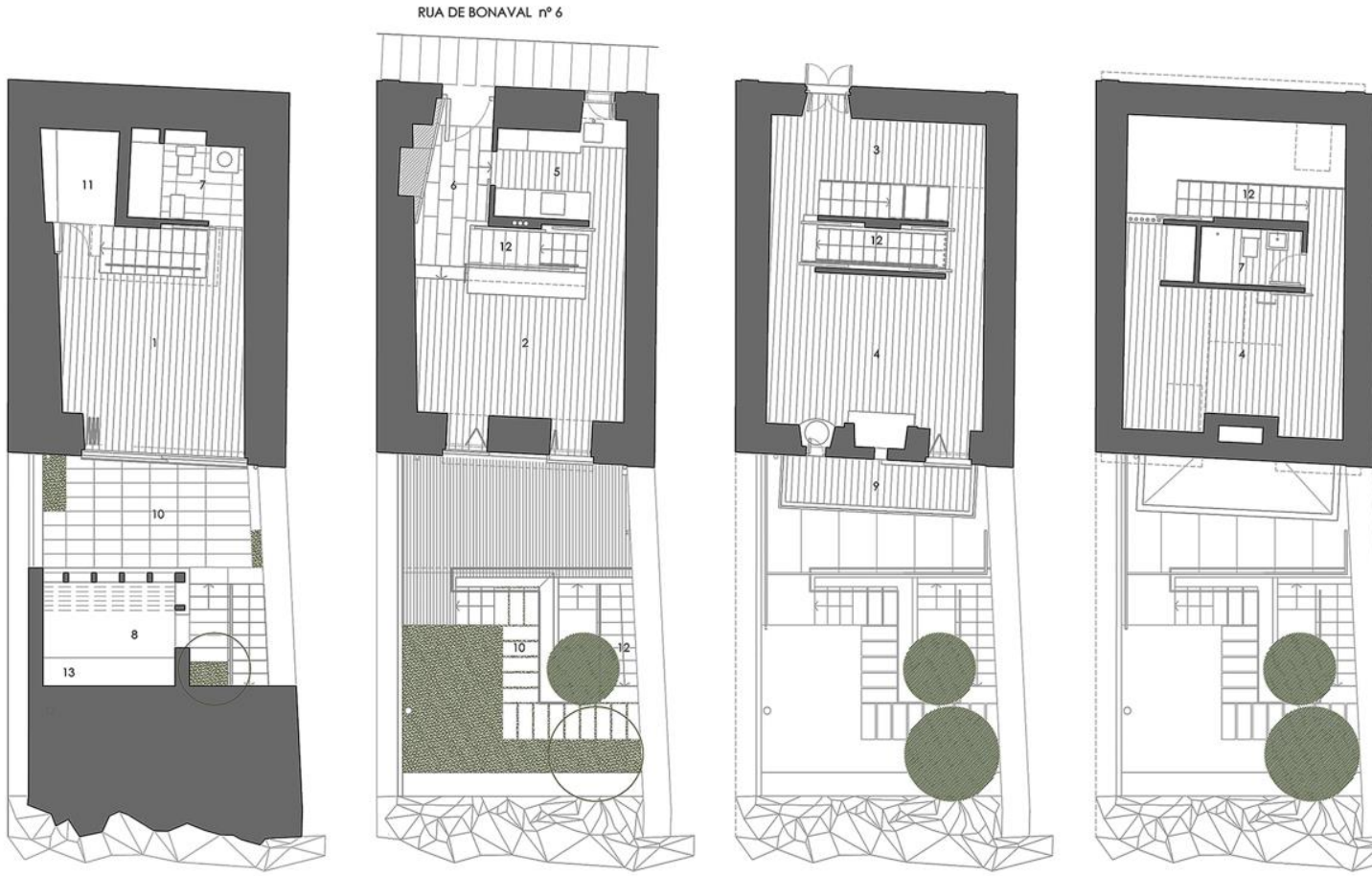

geográficas e topográficas propiciada por uma dúctil utilização do tipo.

Consequentemente, o entendimento dessa 'estrutura formal', nossa interpretação 'poética' da mesma, será determinante.

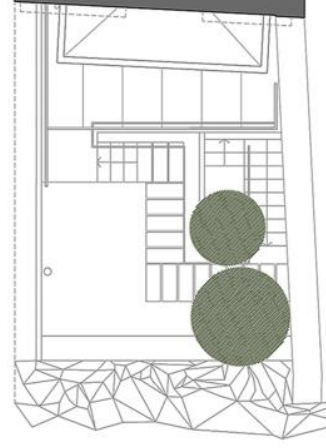

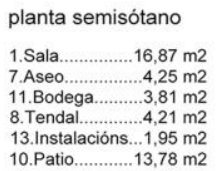
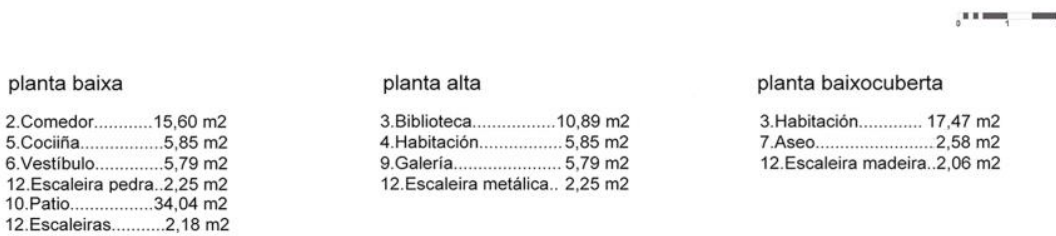

Figura 7. Plantas da moradia. (fonte: elaborada pelo autor).

Em nosso caso (a reestruturação de uma pequena moradia situada no centro histórico de Santiago) o projecto articula-se sobre três ideias principais:

$1^{\circ}$ os muros como elementos estruturais e estruturantes: sua percepção.

$2^{\circ}$ o pátio trasero como elemento fundamental do tipo, em oposição à fachada principal, o que estabelece um eixo longitudinal entre o espaço público e o espaço livre privado: a luz cruzada

$3^{\circ}$ a escada como organizador do espaço, o que formaliza um segundo eixo vertical.
A posta em valor dos muros como elementos estruturais e estruturantes se consegue por um lado com uma proposta racional dos forjados horizontais em relação aos muros portantes; e por outro, desde um ponto de vista espacial, mediante a percepção longitudinal dos muros medianeros, que banhados pela luz entre fachadas desenvolvem toda sua expresividad. Nos muros de fachada manifesta-se outra qualidade: a massa. A espessura dos muros outorga uma grande plasticidade aos ocos, a transição entre interior e exterior realiza-se através de uma ombreira onde a luz é protagonista com todos seus matizes. 


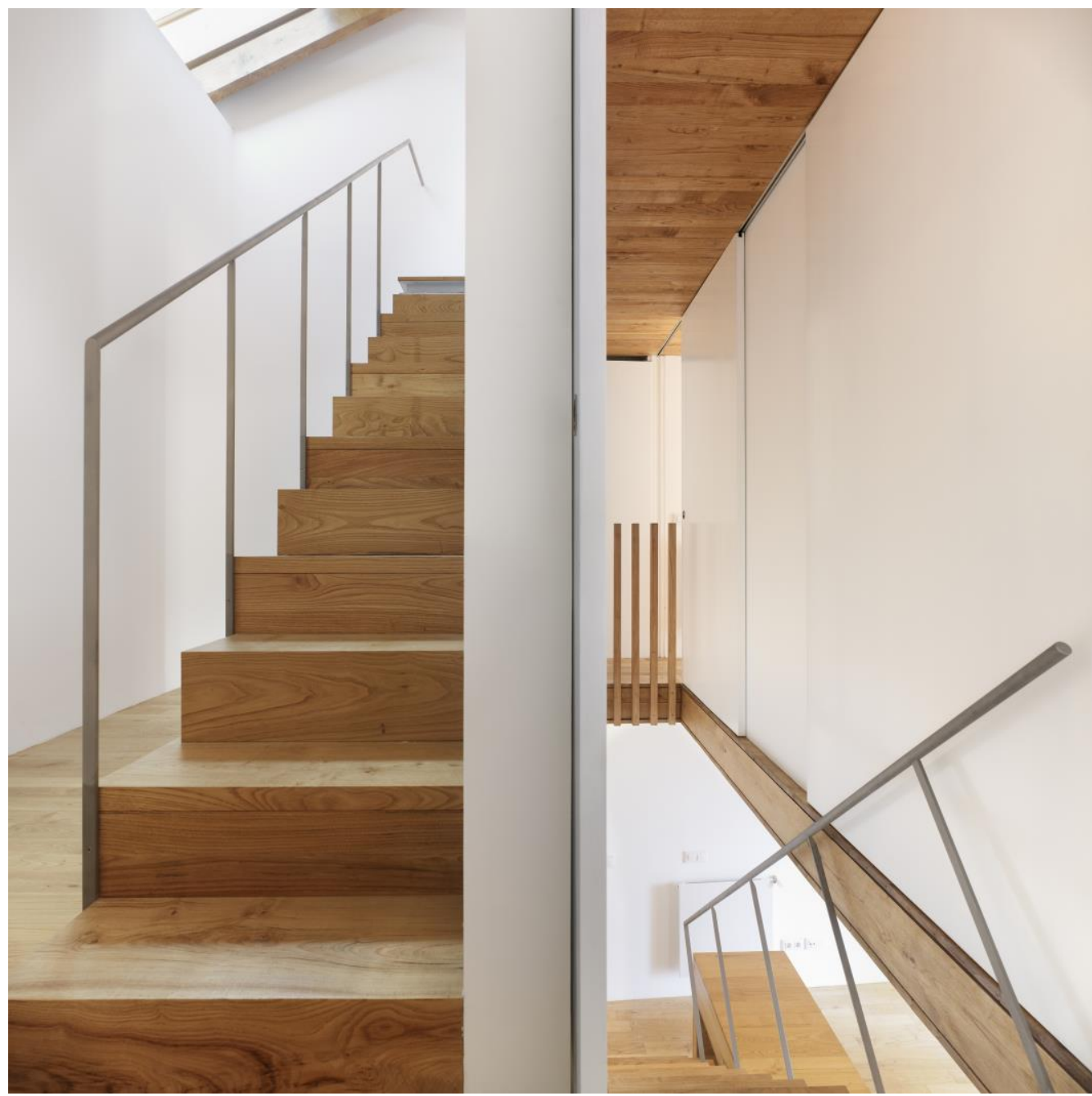

Figura 8. A escada como 'coração' do espaço. (fonte: Héctor Santos Díez, fotógrafo).

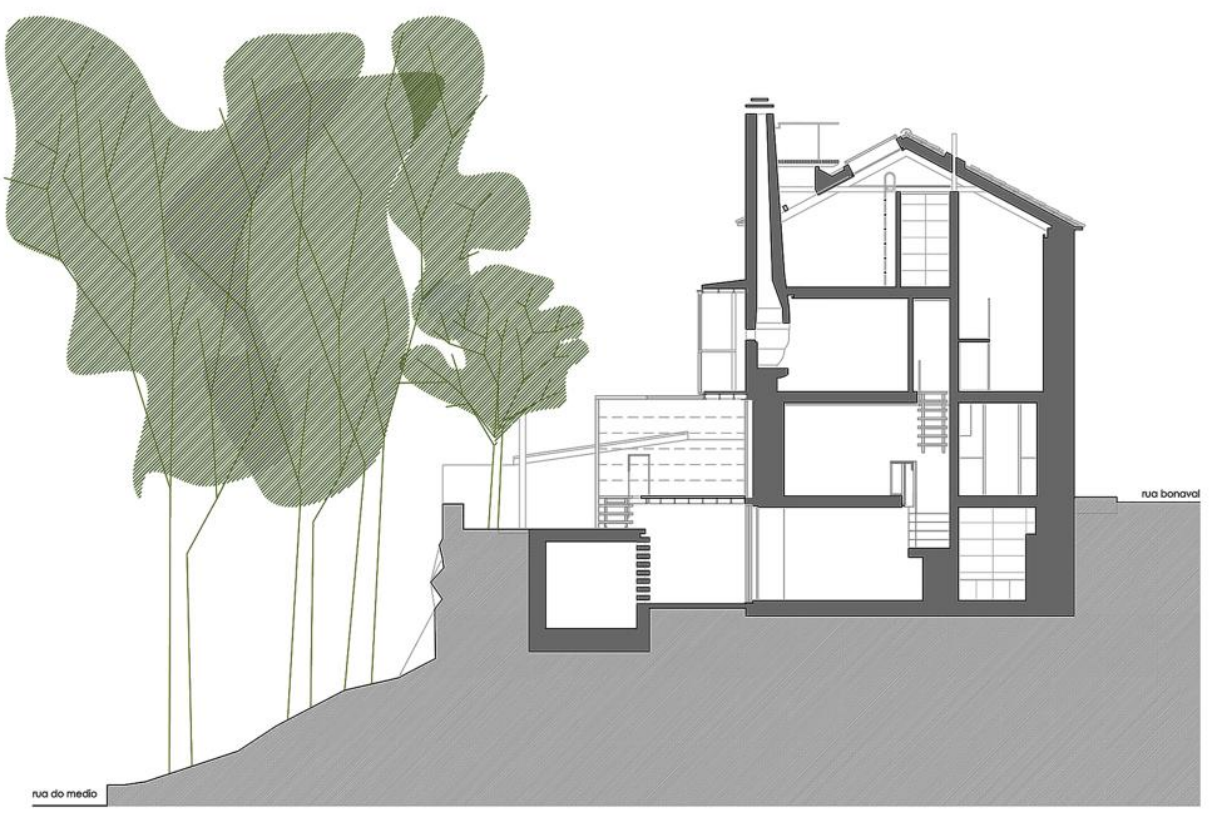

Figura 9. Secção da moradia. (fonte: elaborada pelo autor). 


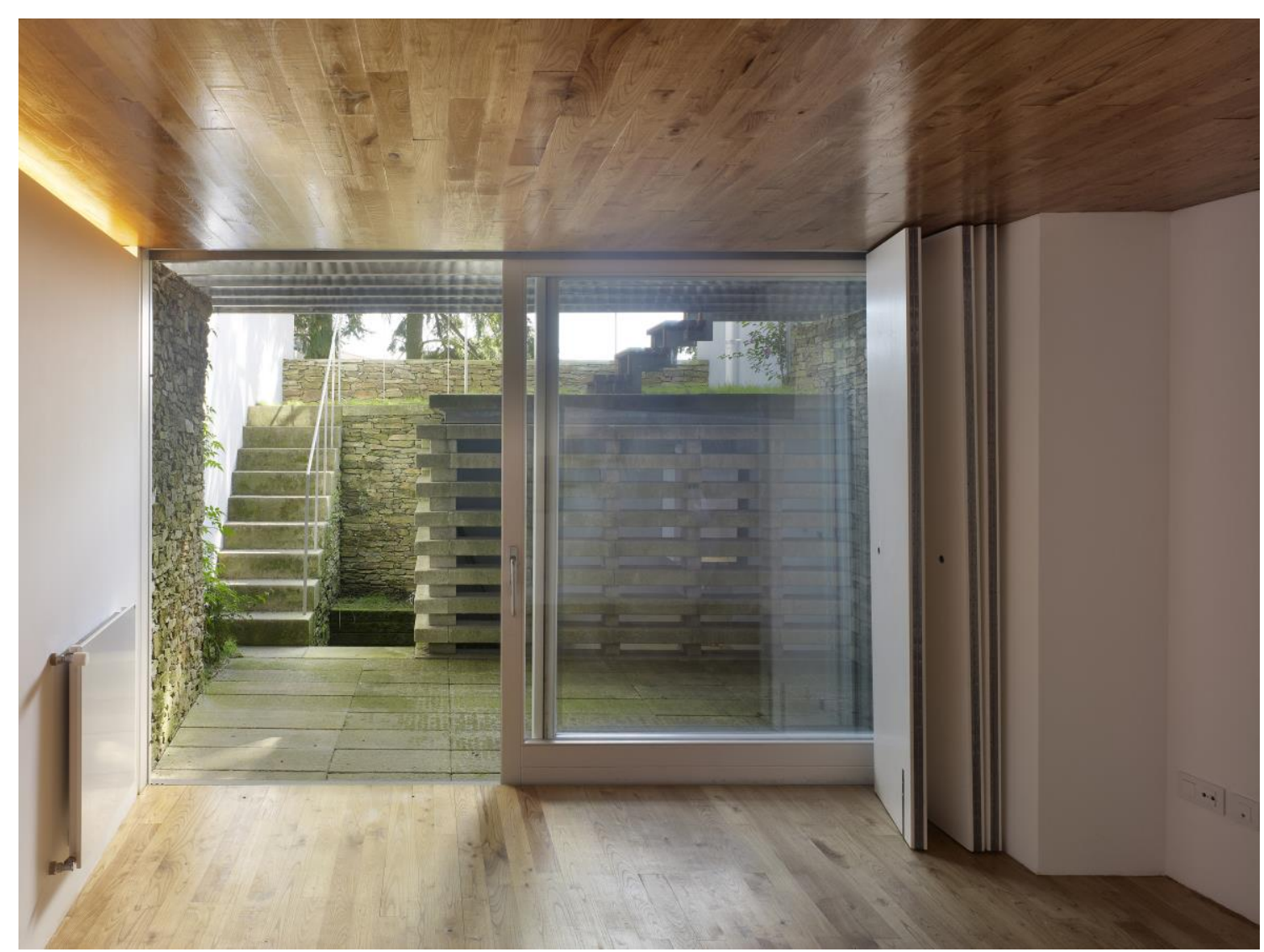

Figura 10. A grande abertura o pátio no semisótano (fonte: Héctor Santos Díez, fotógrafo).

O pátio trasero como elemento fundamental do tipo, em oposição à fachada principal, o que estabelece um eixo longitudinal entre o espaço público e o espaço livre privado. Este eixo é remarcado pela luz que cruza a vivenda entre as duas fachadas.

O pátio modifica seu uso: com um aproveitamento produtivo ou de serviço em suas origens e com uns usos lúdicos ou de esparcimiento na actualidade. Isto supõe um prolongamento da moradia ao exterior, pelo que a fachada trasera -com frequência menosprezada na passado- passa a ter uma relevância especial convertendo na ombreira entre o pequeno jardim e o interior.

A escada formaliza um segundo eixo: 'a casa é imaginada como um ser vertical. Eleva-se' (Bachelard, 1957). A escada articula todo o espaço. A cada trecho cobra personalidade em função da estadia que atravessa, suas qualidades tectónicas mudam; converte-se no 'coração' da moradia. Tentou-se sublinhar estas qualidades do tipo e explorar todo o potencial que a exclusividade topográfica oferecia, dada a grande diferença de cota existente entre a Rúa de Bonaval e a Rúa do Médio. Põe-se o ênfase na expressão dos muros, por um lado na linealidade da medianería e por outro em sua massa, em sua espessura. Esta qualidade faz-se mais patente na fachada trasera ao separar a massa do muro da gravidade, do peso, mediante uma grande abertura no semisótano, que sublinha uma pretendida relação de igualdade entre o pátio e a moradia.

Transforma-se o espaço livre da parcela num 'jardim' ao que se abrem as estadias principais. Quiçá a principal mutación do tipo produz-se ao outorgar à fachada ao pátio a condição de principal. Em mudança, ante as novas condições ambientais derivadas do excessivo tráfico, a fachada à rua considerase um mero acesso. 


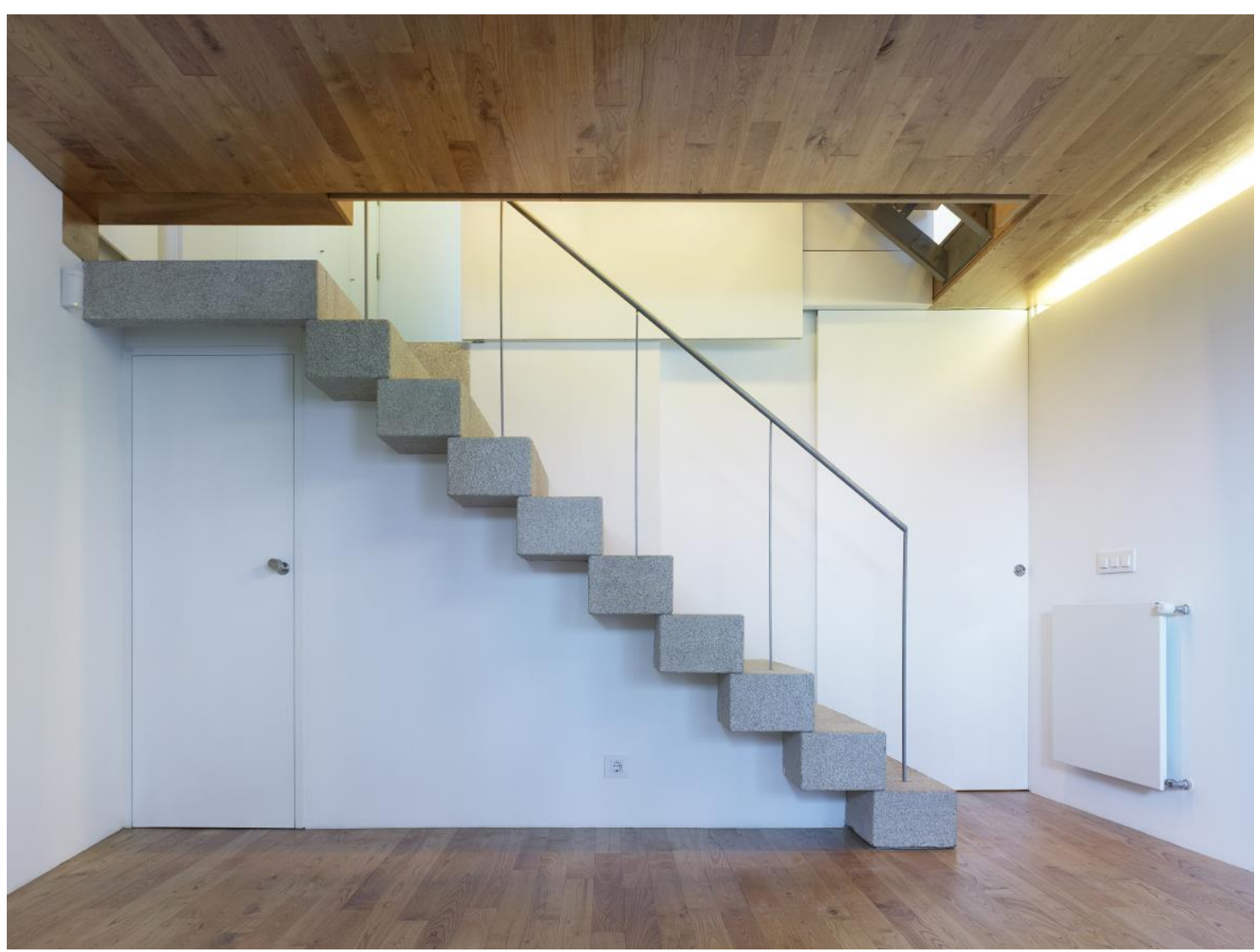

Figura 11. A grande abertura o pátio no semisótano (fonte: Héctor Santos Díez, fotógrafo).

O entendimento do tipo arquitectónico e as lógicas construtivas que implica nos permitiram intervir com critérios absolutamente contemporâneos -respeitando o regulamento que o plano especial do conjunto histórico estabelece para este tipo de edifícios- sempre desde a convicção de que o projecto, ainda quando se trate de uma reabilitação, deve ser considerado uma unidade, um sistema coerente, tanto em seu pensamento e concepção como em sua formalización final. A tradição bem entendida deve ser conceituada como uma evolução tecnológica, que inova e progride desde o entendimento dos critérios construtivos que o passado nos ensina.

Evidentemente estes princípios de partida levam-nos a que a materialización do projecto surja do diálogo entre os três materiais básicos na construção da cidade histórica: a pedra, a madeira e o ferro, desde uma expressão arquitectónica contemporânea que valoriza o rigor construtivo da tradição, mas que incorpora a liberdade que $o$ extraordinário desenvolvimento tecnológico atual propícia. 


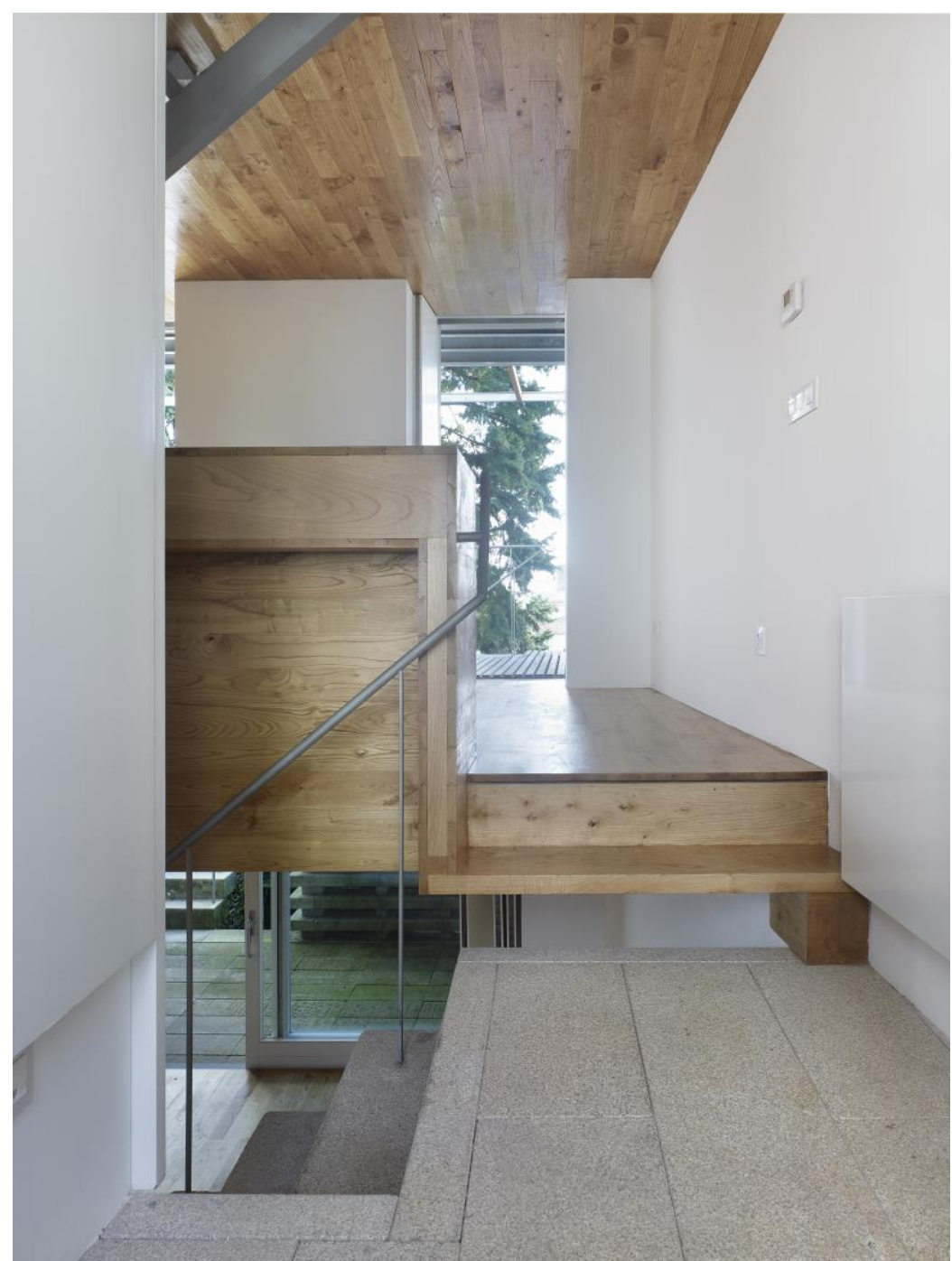

Figura 12. A escada que baixa ao sótano (fonte: Héctor Santos Díez, fotógrafo).

\section{Agradecimentos}

A Carmen, Alma e Olivia por sua paciência e ajuda.

A Juan Luis Dalda, cujas reflexões sobre a cidade de Santiago estão na origem do presente artigo.

A Nestor Rodríguez, a Ana Villegas e a Manuel Muñoz, colaboradores durante o projecto e direcção da obra; e a tuconsa (empresa construtora)

\section{Referências}

Bachelard, G. (1957) La poétique de l'espace. Paris: Presses Universitaires de France.

\section{Notas}

${ }^{1}$ A versão revisada deste artigo foi submetida originalmente até o prazo de 5 de setembro de 2018 aos organizadores do PNUM 2018 Porto. A finalização da seleção inicial dos artigos pela comissão organizadora do evento aconteceu em 30 de maio de 2019 e a seleção final pelos editores da RMU e comunicação aos autores aconteceu em 2 de dezembro de 2019. As versões finais foram enviadas até o dia 9 de fevereiro de 2020.

Dalda, J. L. Viña, A. (1986) (Oficina de Planeamiento S.A.) Levantamiento tipológico de la ciudad histórica de Santiago de Compostela. E: 1:500. Em: Martí, C. (ed.) Santiago de Compostela: La ciudad histórica 
como presente. Santiago, Consorcio de la Ciudad de Santiago de Compostela, 1995.

Martí, C. (1995). La ciudad histórica como presente, un recorrido por la arquitectura de Santiago. - Em: Martí, C. (ed.) Santiago de Compostela: La ciudad histórica como presente.
Santiago, Consorcio de la Ciudad de Santiago de Compostela.

Moneo, R. (1978). On Typology.

Oppositions: summer 1978, 13. Cambridge

Mass.: The MIT Press.

\section{Tradução do título, resumo e palavras-chave}

Topology and typology, the gothic plot

Abstract. The concept of topology is perfectly defined "studies certain properties of geometrical figures, among them those which do not vary when figures are deformed", while the typology has a much broader and indefinite meaning: "study of the characteristic traits of a data set", nevertheless its joint vision helps us to deepen in the understanding of the architectural type. The European historical city has a number of common features: its geographical and topographic adaptation, and a constructive rationality where the stone walls are the fundamental elements. The different road schemes articulate a very varied plotting where the great monumental buildings coexist with the small houses. The elemental unit of this mosaic is the "Gothic plot". In the case of Santiago de Compostela these characteristics are very accentuated and the urban landscape comes determined by the contrast between the tiny housing-derived of the medieval plotting- and the great religious monuments. Thus a simple pattern, based on the relationship between Gothic plot and street, coupled with two very different strategies of topographic adaptation, gives rise to an extraordinarily rich and complex urban structure. The research on the type, which is supported by the realization of a concrete architectural project, is the object of this article.

Keywords: type, patterns, typology, rehabilitation, historical city

Editor responsável pela submissão: Julio Celso Borello Vargas.

Licenciado sob uma licença Creative Commons.

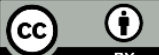

